\title{
Vulva cancer and HIV
}

\author{
Camara Moussa Kantara*, Magaouba Mamoudou, Leno Daniel William Athanase, Bah Thierno Issa, \\ Mohamed Diane, Hyjai Yolande, Keita Namory
}

Obstetrics Gynecology Service, Deputy Head of Department, Head of Service, Conakry

Received: December 01, 2017; Published: December 11, 2017

*Corresponding author: Camara MK, Department of Obstetric and Gynecology, Donka National Hospital, Conakry. Email: camarakanta@gmail.com

Keywords: Cancer; Vulva; Hiv; Donka

\section{Summary}

The authors report a rapid progression in 7 weeks, illustrated, of invasive squamous cell carcinoma of the vulva in a 42 -yearold woman living with HIV, whose serologic status was unknown before receiving her and starting ARV and palliative treatment, with a review of the literature.

\section{Introduction}

Vulvar carcinoma is more and more common, especially in young patients because of viral infections. The objective of the study was to report images of a rapid onset of epidermoid carcinoma on HIV 1, unknown and untreated.

\section{Observation}

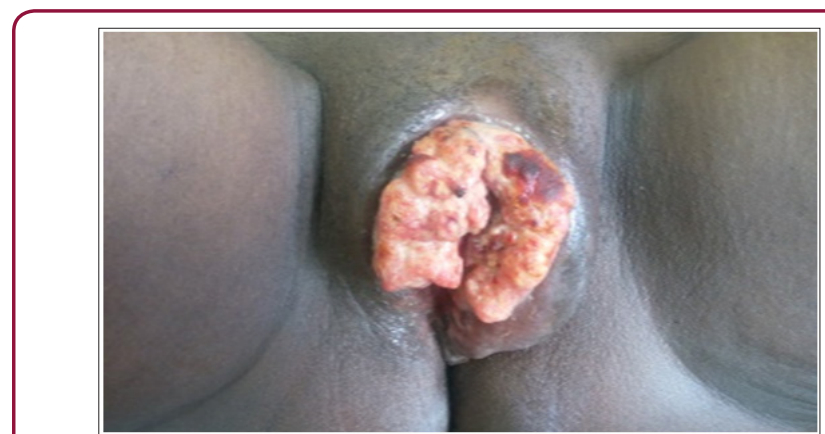

Figure-1

It was Mrs. SB, aged 42, married, primigeste, with a history of menarche at 14 years, twin birth and concept of low genital infection, received at the oncological consultation of 24/05/2017, for vulvar swelling evolving for 3 months. A examination, it had a vulva tumor budding $6 \times 6 \mathrm{~cm}$, interesting the 2 lips, the entire left lip and $2 / 3$ of the right with infiltration of the bladder trine, inguinal ganglia indurated and a flow of odorless pus at the pressure of the tumor (Figure 1) at that date, colposcopy was normal. The diagnosis of suspected neoplasia of the vulva with destruction of the lips (large and small) was posed with biopsy samples and a request for paraclinical investigations exploring the field, after counseling on neoplasia and on the possible positivity of testing for sexually transmitted diseases including HIV.

As of $12 / 07 / 2017$, it was reviewed with worsening and infiltration of the entire vulva to Mont the venus [Figure 2] and histological confirmation results (of appearance corresponding to invasive squamous cell carcinoma of the vulva), serology positive for HIV 1 and TPHA / RPR (syphilis), CD4 count at 265 / mm3, CRP positive at $80 \mathrm{mg} / \mathrm{dl}$ and moderate anemia at $9 \mathrm{~g} / \mathrm{dl}$. A palliative treatment was offered to him with his orientation, after counseling, in the house of his treatment day with Anti Retro Virus (ARV).

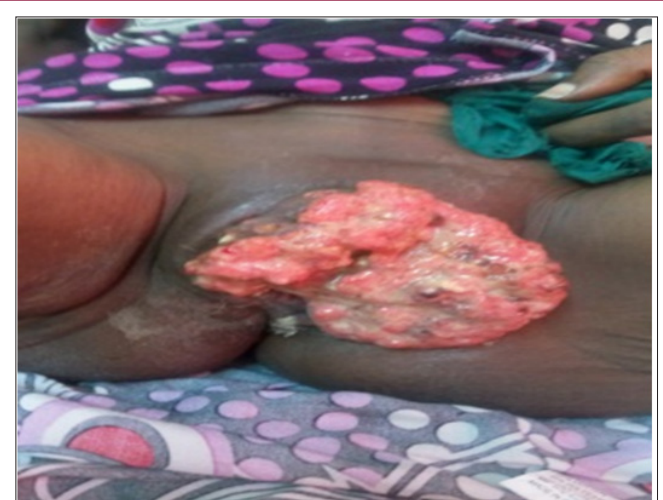

Figure-2

\section{Comments}

The three-month delay in the diagnosis of our case and that of Amourak [1], would be linked to the patient's ignorance of the sexually transmitted infections with ulceration, premary signs such as pruritus, swelling (our case), evolution and severity of the cancerous disease and its HIV status. Vulvar cancer appeared in a young woman under 50 years old instead of 70 years old. The frequency of HIV-related tumors increases 20 years younger 
than in the general population [2]. This increase in the number of young people is linked to the observation of human papillomavirus (HPV) infections [3] and HIV [4]. Syphilitic lesions would be the gateway to HIV infection including a drop in CD4 count and acute outbreak of historical vulvar cancer between 2 visits at 7 week intervals without treatment. Delay in diagnostic confirmation can be linked to poverty and the lack of integration of HIV testing and management into cancer consultation. The vulvar smear on primary lesions of the vulva for an early diagnosis of precancerous lesions and their correct treatment in medical, gynecological or dermatological environment, could improve the prognosis of the patients of this association.

\section{Conclusion}

The association cancer of the vulva and HIV is rare. She had a rapid course in a woman in 7 weeks. The sensitization of the population, education for self-examination, the treatment of precancerous lesions and the risk of HIV infection would allow earlier diagnosis.

\section{Medical Images}

About a rapid evolutionary thrust of vulvar cancer and historical HIV at the Gynecological Obstetrics Department of Donka National Hospital, Conakry, Guinea.

\section{References}

1. Amoura $\mathrm{k}$ and Alaoui F F A. Neo vulva in an HIV positive HIV patient about a historical case NCBI-NH.

2. Berriche A. HIV related tumors.

3. Canadian Cancer Society. Risk Factors for Vulvar Cancer.

4. Casolati E, Agarossi A, Valieri M and FerrazziE (2003) Vulvar neoplasia in positive hiv women: areview. MedWiekuRozwoj 7(4 Pt 1): 487-493.

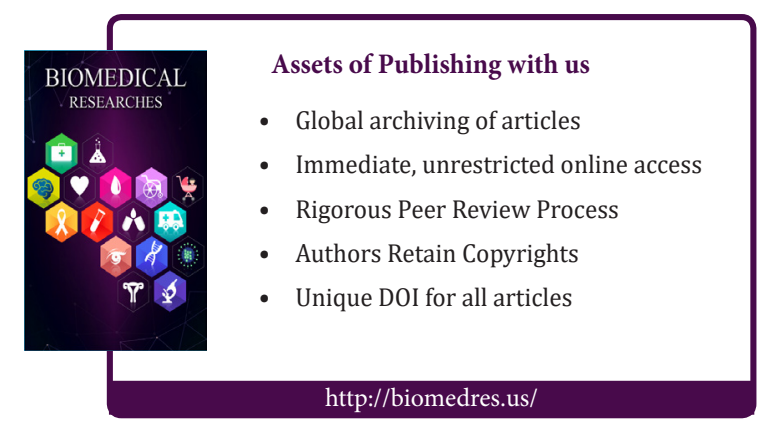

